\title{
Improved Accuracy of Low Affinity Protein-Ligand Equilibrium Dissociation Constants Directly Determined by Electrospray Ionization Mass Spectrometry
}

\author{
Lucie Jaquillard, ${ }^{1}$ Fabienne Saab, ${ }^{1}$ Françoise Schoentgen, ${ }^{2}$ Martine Cadene ${ }^{1}$ \\ ${ }^{1}$ Centre de Biophysique Moléculaire, CNRS UPR 4301, affiliated with Université d'Orléans, rue Charles-Sadron, 45071 \\ Orléans, Cedex 2, France \\ ${ }^{2}$ Institut de Minéralogie et de Physique des Milieux Condensés, CNRS UMR 7590, Université de Paris 6, 75252 Paris, Cedex \\ 5, France
}

\begin{abstract}
There is continued interest in the determination by ESI-MS of equilibrium dissociation constants $\left(K_{D}\right)$ that accurately reflect the affinity of a protein-ligand complex in solution. Issues in the measurement of $K_{D}$ are compounded in the case of low affinity complexes. Here we present a $\mathrm{K}_{\mathrm{D}}$ measurement method and corresponding mathematical model dealing with both gas-phase dissociation (GPD) and aggregation. To this end, a rational mathematical correction of GPD ( $\left.f_{\text {sat }}\right)$ is combined with the development of an experimental protocol to deal with gas-phase aggregation. A guide to apply the method to noncovalent protein-ligand systems according to their kinetic behavior is provided. The approach is validated by comparing the $K_{D}$ values determined by this method with in-solution $K_{D}$ literature values. The influence of the type of molecular interactions and instrumental setup on $\mathrm{f}_{\text {sat }}$ is examined as a first step towards a fine dissection of factors affecting GPD. The method can be reliably applied to a wide array of low affinity systems without the need for a reference ligand or protein.
\end{abstract}

Key words: Accuracy, Equilibrium dissociation constant, KD, Gas phase dissociation, Aggregation, ESI, Model, Low affinity, Interaction, Protein-ligand, Mass spectrometry

\section{Introduction}

$\mathrm{M}$ ost of the cell functions that endow organisms with sustainable life rely on the interaction of proteins with each other, nucleic acids, glycans, lipids, or small molecules. The formation of a protein-ligand complex is generally mediated by noncovalent contacts, including hydrogen

Electronic supplementary material The online version of this article (doi:10.1007/s13361-011-0305-7) contains supplementary material, which is available to authorized users.

Correspondence to: Martine Cadene; e-mail: cadene@cnrs-orleans.fr bonds, ionic bonds, van der Waals interactions, and interactions based on the hydrophobic effect. The proteinligand equilibrium dissociation constant $\mathrm{K}_{\mathrm{D}}$ is an essential parameter used to describe a binding system, and to provide relative affinity information between ligands or between target proteins. The $\mathrm{K}_{\mathrm{D}}$ can generally be determined by a biophysical method such as isothermal titration calorimetry, spectrophoto- or spectrofluorimetry, or surface plasmon resonance. In these techniques, $K_{D}$ is determined by measurement of an incident property of the complex resulting from binding. Measuring the $\mathrm{m} / \mathrm{z}$ of complex ions by MS is the only method allowing for the direct measurement of a fundamental physical dimension of the 
complex, in this case its mass. Following seminal work by Ganem and coworkers [1,2] and Katta and Chait [3] for noncovalent complex detection, direct infusion electrospray ionization mass spectrometry (ESI-MS) has emerged as a powerful technique for quantifying the equilibrium dissociation constant $\mathrm{K}_{\mathrm{D}}$ for protein-ligand interactions [4-6]. The search for accurate methods for $\mathrm{K}_{\mathrm{D}}$ determination has also led to the development of indirect methods based on HDX and mass spectrometry (MS), such as PLIMSTEX [7] and SUPREX [8].

The direct ESI-MS $\mathrm{K}_{\mathrm{D}}$ determination technique is based on the direct detection and quantification of PL (proteinligand complex) and $\mathrm{P}$ (unbound protein) ions in the gas phase. A key assumption for this type of experiment is that the bound fraction ( $f_{\text {bound }}$ ) measured by MS is equivalent to the $f_{\text {bound }}$ at equilibrium in solution. The classical quadratic Equation [9] establishes the relationship between $\mathrm{f}_{\text {bound }}$, the ratio of bound protein concentration over total protein concentration, which is the measured variable, $\mathrm{K}_{\mathrm{D}}$, the protein-ligand equilibrium dissociation constant to be determined, and $[\mathrm{P}]_{0}$ and $[\mathrm{L}]_{0}$, the initial protein and ligand concentrations, respectively:

$\mathrm{f}_{\text {bound }}=\frac{[\mathrm{P}]_{0}+[\mathrm{L}]_{0}+\mathrm{K}_{\mathrm{D}}-\sqrt{\left([\mathrm{P}]_{0}+[\mathrm{L}]_{0}+\mathrm{K}_{\mathrm{D}}\right)^{2}-4[\mathrm{P}]_{0}[\mathrm{~L}]_{0}}}{2[\mathrm{P}]_{0}}$

The equilibrium dissociation constant $\mathrm{K}_{\mathrm{D}}$ can be determined by nonlinear regression analysis on a $[\mathrm{L}]_{0}, \mathrm{f}_{\mathrm{bound}}$ dataset using Equation (1), where $[\mathrm{L}]_{0}$ is the $\mathrm{x}$ input variable and $\mathrm{f}_{\text {bound }}$ is the $\mathrm{y}$ variable. However, the $\mathrm{f}_{\text {bound }}$ measured in the gas phase reflects not only the solution-binding fraction, but also phenomena related to the transfer of the complex into the gas phase. These phenomena generate issues in the measurement of $\mathrm{K}_{\mathrm{D}}$, which are compounded in the case of low affinity complexes. First, the protein-ligand complex can be susceptible to partial dissociation in the interface of the instrument. This phenomenon is widely known as gasphase dissociation (GPD). Avoiding GPD can be quite challenging [10-12]. As a consequence of GDP, the bound fraction tends to be underestimated. Second, the presence of free protein and ligand molecules in the electrospray droplet results in gas-phase aggregation, i.e., the formation of nonspecific protein-ligand complexes upon evaporation of the droplet. This is of concern particularly for low affinity systems which, in contrast to high-affinity systems, necessitate the addition of a significant excess of ligand to produce a measurable bound fraction. Protein-ligand complexes can be considered as low affinity if $K_{D} \geq 1 \mu \mathrm{M}$. As a consequence of gas-phase aggregation, the observed complex stoichiometry is altered compared with the solution-phase stoichiometry [2]. Moreover, aggregation can lead to false positives and has been shown to result in artificially low $K_{D}$ values [13]. Different strategies have been developed to determine the $K_{D}$ of low affinity complexes by ESI-MS. One strategy consists in disrupting aggregation using black-body infrared radiation dissociation (BIRD) [14]. However, in cases where gas-phase aggregation is stronger than the specific interaction, this strategy leads to the destruction of the complex of interest [15]. The Daubenfeld/van der Rest method [16] is based on the hypothesis that specific ligand binding follows a statistical distribution, which is different from the distribution of nonspecific, aggregation-related binding modes. By deconvoluting the raw binding fraction data into separate distributions, the authors can calculate the contribution of specific binding to the interaction. Strategies based on the use of a reference protein, which is known to lack specific binding for the ligand of interest, have been used to quantify aggregation [17]. Alternatively, competitive assays with a reference ligand have been developed as a quantitative method to deal with aggregation [18]. The main limit of all these strategies is that they correct for aggregation without taking into account potential GPD phenomena.

To deal with gas phase dissociation, thermal heating, cone voltage and pressure in the first pumping stage are usually optimized to preserve the noncovalent complex [1921]. Certain solvent additives promote evaporative cooling, thereby enhancing the survival probability of some weakly bound species $[12,22]$. Competition experiments with a reference ligand can be used to compensate for variable response factors [23]. None of the above strategies to correct potential GPD deals explicitly with the aggregation issue.

$\mathrm{K}_{\mathrm{D}}$ determination methods simultaneously dealing with both the GPD and aggregation issues have not been previously described. Here we present a complete MS-based approach with the aim to determine a $\mathrm{K}_{\mathrm{D}}$, which accurately reflects the affinity in solution. To this end, a mathematical correction of GPD based on a rational examination of solution-to-gas transfer events is combined with the development of a new experimental protocol to deal with gas-phase aggregation. Moreover, we examine in detail the consequences of the introduction of a micropurification step on the behavior of the complex prior to analysis, and develop appropriate equations for the $\mathrm{K}_{\mathrm{D}}$ determination. A guide to apply the method to noncovalent protein-ligand systems according to their kinetic behavior is provided. The approach is validated by comparing the $K_{D}$ values determined by this method with literature values determined in solution on reference protein-ligand systems. Furthermore, the influence of the type of molecular interactions and of the instrumental setup on GPD is examined as a first step towards a fine dissection of factors affecting GPD.

\section{Experimental}

\section{Materials}

Bovine pancreatic ribonuclease A (RNase A), hen egg-white lysozyme (HEWL), guanosine triphosphate (GTP), flavin mononucleotide (FMN), adenosine diphosphate (ADP), 
cytosine triphosphate (CTP), tri- $N$-acetylchitotriose (NAG3), ammonium bicarbonate $(\mathrm{ABC})$, and tris-(2-carboxyethyl) phosphine (TCEP) were purchased from Sigma (St. Louis, MO, USA). Ammonium acetate $\left(\mathrm{NH}_{4} \mathrm{OAc}\right)$ was purchased from Merck (Darmstadt, Germany). $\beta$-Mercaptoethanol was obtained from Amersham Biosciences (Uppsala, Sweden) and rabbit muscle creatine kinase (CK) from Roche (Mannheim, Germany). Tuning Mix, a mixture of fluorinated phosphazenes reference G2421A was from Agilent Technologies (Santa Clara, CA, USA). Acetonitrile was procured from Carlo Erba (Milan, Italy) and formic acid 90\% (FA) from Fisher (Loughborough, UK). The P3P triphosphorylated peptide from Raf-1 with the sequence RPRGQRDpSpSYpYWEIEASEV was a product of Fmoc synthesis. Details of the synthesis strategy will be described elsewhere. All solvents and buffers were prepared using $18 \mathrm{M} \Omega$ purified water (MilliQ reagent grade system, Millipore, Billerica, MA, USA).

\section{hPEBP and Nucleotides Purification}

Recombinant human phosphatidyl ethanolamine binding protein (hPEBP), with an average $\mathrm{M}_{\mathrm{r}}$ of 20,925.6 Da, was cloned and overexpressed in BL21DE3 E. coli as described by Schoentgen and coworkers [24]. The tagless protein was purified by QAE Sephadex A-50 chromatography, isoelectrofocusing, and Blue-Sepharose chromatography, as previously described [25]. Between purification steps, the protein was concentrated by centrifugation at $4000 \mathrm{~g}$ for $20 \mathrm{~min}$ using a Vivaspin centrifugal separation vial with a $3 \mathrm{kDa}$ cut-off filter (Sartorius Stedim, Aubagne, France). The purified protein was initially stored in a solution of $20 \mathrm{mM}$ MES, $1 \mathrm{mM} \beta$-mercaptoethanol. As $\beta$-mercaptoethanol was found by MS to form covalent adducts with hPEBP by targeting the protein's free cysteines [26], a procedure for the removal of $\beta$-mercaptoethanol by various reducing agents was developed. The addition of TCEP to hPEBP stock solutions at a final concentration of $1 \mathrm{mM}$ for one hour at $37{ }^{\circ} \mathrm{C}$ efficiently reduced the $\beta$-mercaptoethanol-cysteine bond [27]. The reduced protein solution was then dialyzed against water using Micro Dispodialyzer (Harvard Apparatus, Holliston, MA, USA) with a $10 \mathrm{kDa}$ cut-off to eliminate excess TCEP. Purified hPEBP was stored in milliQ water with 2 equivalents of TCEP at $-80^{\circ} \mathrm{C}$.

Commercial GTP, FMN, ADP and CTP nucleotides used in this study were desalted to prevent $\mathrm{Na}^{+}$adduct formation. For this purpose, a protocol derived from the RNA-desalting procedure of Limbach et al. was set up [28]. Desalting of nucleotide water solutions was achieved by precipitation in the presence of $2.5 \mathrm{M}$ ammonium acetate and $70 \%$ ethanol at room temperature. The supernatant was discarded and the pellet dissolved in water for MS monitoring of adduct formation. After one to three precipitation cycles, the pellet was dried without heat in a Speed-Vac apparatus (Thermo Scientific, Waltham, MA, USA). Stock solutions at $5 \mathrm{mM}$ in milliQ water were stored at $-80{ }^{\circ} \mathrm{C}$.

\section{Micro Gel Filtration (MGF)}

Micro gel filtration spin columns (Zeba, Thermo Scientific) with a $7 \mathrm{kDa}$ cut-off were used to desalt $\mathrm{CK}$ and RNase A and, where applicable, to eliminate excess ligand after incubation with the protein. Spin columns with a bed volume of 75 or $500 \mu \mathrm{L}$ were used. Efficient elimination of the conditioning buffer from the gel filtration phase required five cycles of equilibration with volumes of 50 or $300 \mu \mathrm{L}$ of incubation buffer, respectively. The sample was loaded onto the spin column and the collection performed immediately with a $30 \mathrm{~s}$ centrifugation at $1000 \times \mathrm{g}$ or $1500 \times \mathrm{g}$, respectively.

\section{Sandwich Infusion Method}

To limit protein consumption, a "sandwich" infusion method was developed. The syringe was filled with a volume of 10 $\mu \mathrm{L}$ of sample trapped between volumes of solvent. The front solvent is used to clear the dead volume of the system, while the back solvent is used to push the sample into the source. Samples were infused at a flow rate of $1.3 \mu \mathrm{L} / \mathrm{min}$. Proteins in non-denaturing buffer analyzed with $\mathrm{H}_{2} \mathrm{O}$ :ACN:FA 49.8:50:0.2 ( $\mathrm{vol} / \mathrm{vol})$ as a sandwich solvent exhibited a wide bell-shaped charge state distribution while proteins analyzed with non-denaturing buffer as sandwich solvent exhibited the high $m / z$, very narrow charge state distribution which is typical of native species [29]. Therefore, to preserve the native structure of the protein, non-denaturing buffer was systematically used for sandwich infusion.

\section{Mass Spectrometry}

All MS measurements were performed in an ESI-ion trap model Ultra HCT PMT Discovery or Esquire HCT (Bruker, Bremen, Germany), or in a $4 \mathrm{GHz}$ maXis ESI-UHR-QqTOF (Bruker). $\mathrm{K}_{\mathrm{D}}$ measurement and kinetics experiments were performed by preparing solutions containing a fixed concentration of protein with a gamut of ligand concentrations. After incubation, samples were treated by MGF prior to MS measurement, or analyzed directly in MS. Samples were introduced using the above "sandwich" infusion method with a nebulizer gas pressure of $10 \mathrm{psi}$ and a heated glass-capillary temperature of $120{ }^{\circ} \mathrm{C}$.

On the ESI-ion traps the spray voltage was set to $-3.4 \mathrm{kV}$, the dry gas flow to $5 \mathrm{~L} / \mathrm{min}$. For native protein ions detection, the capillary-skimmer voltage difference was adjusted to optimize detection of high $\mathrm{m} / \mathrm{z}$ peaks and to preserve the noncovalent interactions between the protein and the ligand. Data was acquired at $8100 \mathrm{~m} / \mathrm{z} \cdot \mathrm{s}^{-1}$ for a minimum of 2 min using EsquireControl ver. 6.2 software (Bruker), and processed using DataAnalysis ver. 4.0 SP2 (Bruker). The maXis was run using a spray voltage of $-4 \mathrm{kV}$ and a dry gas flow of $4 \mathrm{~L} / \mathrm{min}$. The isCID parameter was adjusted to preserve noncovalent interactions between the protein and the ligand and, in the case of $\mathrm{CK}$, between dimer 
subunits. Data was acquired at 0.2 or $1 \mathrm{~Hz}$ for a minimum of 2 min using micrOTOFcontrol ver. 3.1 (Bruker) and processed using DataAnalysis ver. 4.0 SP4 (Bruker). Peak intensities were used for the calculation of bound fractions as follows:

$$
\mathrm{f}_{\text {bound }}=\frac{\Sigma_{n} \mathrm{I}\left(\mathrm{PL}^{\mathrm{n}+}\right)}{\Sigma_{n} \mathrm{I}\left(\mathrm{PL}^{\mathrm{n}+}\right)+\mathrm{I}\left(\mathrm{P}^{\mathrm{n}+}\right)}
$$

where I represents the intensity on the mass spectrum, PL and $\mathrm{P}$, the protein-ligand complex and the free protein, respective$\mathrm{ly}$, and $\mathrm{n}$, the ion charge state. Nonlinear regression analyses were performed using Kaleidagraph ver. 4.1.0. Errors are given as residual standard errors from the least-square regression process. To determine the error on $K_{D}$ independently of the error introduced by floating a second parameter $\left(f_{\text {sat }}\right)$ in Equation (3) or (13) for the sake of direct comparison with the error on $K_{D}$ determined using Equation (1), the $f_{\text {sat }}$ value found by regression was re-injected as a constant and a second round of regression performed. This produces the same $\mathrm{K}_{\mathrm{D}}$ value with the same $\mathrm{R}^{2}$ as the first round of regression.

\section{Results and Discussion}

\section{Correcting for Gas-Phase Dissociation}

The present study was initiated with the examination of the binding of hPEBP to nucleotides, for which relative affinities had been evaluated but $\mathrm{K}_{\mathrm{D}}$ values were unknown [30]. The cone voltage parameter was optimized to improve the transmission of ions of high mass-to-charge ratio and to preserve noncovalent interactions by limiting concomitant dissociation. To investigate the binding of hPEBP to FMN, the equilibrium dissociation constant was determined by increasing FMN concentration while hPEBP concentration was kept constant. The bound fraction plotted as function of ligand concentration (Figure 1) does not tend to 1 as expected, appearing instead to plateau below 0.5 (dashed line). This observation indicates that only a fraction of complexes in solution is preserved during analysis in the gas phase and that gas-phase dissociation (GPD) occurs in spite of the cone voltage optimization. Even in the gentlest conditions, some amount of dissociation could not been prevented. As a consequence, the image of the equilibrium observed in the gas phase does not directly reflect the equilibrium in solution. Accordingly, when parameters of the classical equation (Equation (1)), which does not take into account the apparent partial dissociation in the gas phase, are fitted by nonlinear regression analysis to FMN-hPEBP binding data points, the fit is poor $\left(\mathrm{R}^{2}=0.83\right.$ ) (Figure 1a).

To account for this phenomenon, we decided to attempt to correct for the partial GDP. For this purpose, we empirically introduced a floating parameter, which we called $f_{\text {sat }}$, which would correspond to the experimental bound fraction at saturation. If we hypothesize that partial GPD is constant throughout the experiment, we
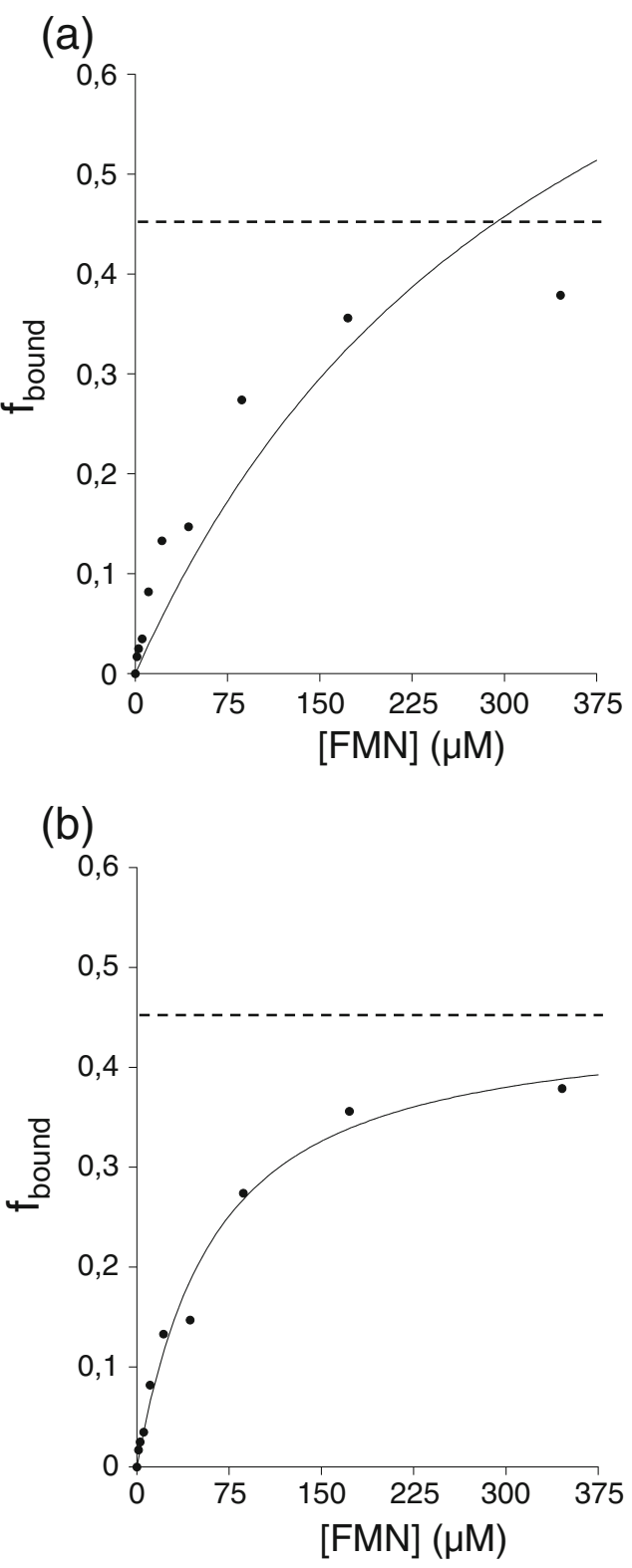

Figure 1. MS-measured bound hPEBP fraction as a function of FMN concentrations following incubation of $12.6 \mu \mathrm{M}$ hPEBP with 0-346 $\mu \mathrm{M}$ FMN at $37{ }^{\circ} \mathrm{C}$ in $20 \mathrm{mM}$ ammonium bicarbonate, $\mathrm{pH}$ 8.4. Equation parameters were fitted to the data by nonlinear regression analysis using (a) Equation (1) to determine $K_{D}$ without GPD correction $\left(K_{D}=349 \pm 55 \mu M ; R^{2}=\right.$ 0.83); and (b) Equation (3) to determine $\mathrm{K}_{\mathrm{D}}$ while applying GPD correction $\left(K_{D}=54 \pm 10 \mu \mathrm{M}, f_{\text {sat }}=0.45 ; R^{2}=0.99\right)$

can introduce the $\mathrm{f}_{\text {sat }}$ parameter as a multiplier in Equation (1), thus yielding Equation (3):

$$
\mathrm{f}_{\text {bound }}=\mathrm{f}_{\text {sat }} \cdot \frac{[\mathrm{P}]_{0}+[\mathrm{L}]_{0}+\mathrm{K}_{\mathrm{D}}-\sqrt{\left([\mathrm{P}]_{0}+[\mathrm{L}]_{0}+\mathrm{K}_{\mathrm{D}}\right)^{2}-4[\mathrm{P}]_{0}[\mathrm{~L}]_{0}}}{2[\mathrm{P}]_{0}}
$$

The above data points were fitted with this corrected equation. Nonlinear regression analysis with Equation (3) 
gave a much better fit, with $\mathrm{R}^{2}=0.99$. In this case, a value of $\mathrm{f}_{\text {sat }}=0.45$ is found, in keeping with our empirical estimate (Figure 1b). The correlation coefficient is much higher with Equation (3) than with Equation (1), confirming our hypothesis that GPD is uniform throughout the experiment. Even in optimized transmission conditions, there is still 55\% of dissociation in the gas phase in our ion trap instrument. Thus, it is crucial to take into account GPD in MS to estimate a $K_{D}$, which best reflects the $K_{D}$ in solution. For the hPEBP-FMN system, correcting the GPD changes $K_{D}$ by a factor of six.

It should be noted that the ratio of bound protein over free protein is often reported as the measured quantity, as it can be conveniently computed directly from the ratio of spectral PL and P intensities. However, this does not allow for the direct detection of the bound fraction at saturation. In contrast, as shown above, the measurement of the ratio of the bound protein over total protein makes the evaluation of the presence of GPD straightforward.

Dissociation in the gas phase can be considered as an irreversible step undergone by a fraction of the complex in the course of solution-to-gas transfer (Scheme 1):

$$
\mathrm{PL}_{\text {sol }} \rightarrow \mathrm{P}_{\mathrm{GPD}}+\mathrm{L}_{\mathrm{GPD}}
$$

Scheme 1. Solution to gas-phase transfer reaction

where the complex in solution $\left(\mathrm{PL}_{\mathrm{sol}}\right)$ partially dissociates in the gas phase to give free protein $\left(\mathrm{P}_{\mathrm{GPD}}\right)$ and free ligand $\left(\mathrm{L}_{\mathrm{GPD}}\right)$. If we define $\mathrm{t}_{\mathrm{GPD}}$ as the amount of time in which the complex can undergo dissociation in the instrument interface, the $[\mathrm{PL}]_{\mathrm{sol}}\left(\mathrm{t}_{\mathrm{GPD}}\right)$ expression corresponds to the complex surviving the solution-to-gas transfer. We call the intact gas-phase complex $\mathrm{PL}_{\mathrm{G}}$ :

$$
[\mathrm{PL}]_{\mathrm{sol}}\left(\mathrm{t}_{\mathrm{GPD}}\right)=[\mathrm{PL}]_{\mathrm{G}}
$$

To keep $t_{(G P D)}$ constant, it is essential to keep the instrument voltages and spray conditions unchanged over the course of $K_{D}$ measurements. Provided that this condition is respected, we have shown that dissociation in the instrument is constant throughout the experiment and that the decrease in complex ions population is proportional to the complex population in solution.

This translates mathematically as:

$$
[\mathrm{PL}]_{\mathrm{G}}=[\mathrm{PL}]_{\mathrm{sol}} \cdot \mathrm{f}_{\mathrm{sat}}
$$

Dividing both sides of the equation by the total protein concentration, Equation (5) combined with Equation (1) gives Equation (3). Namely, the binding fraction measured in the gas-phase reflects both GPD and the binding fraction in solution.

\section{Dealing with Gas-Phase Aggregation}

Gas-phase aggregation is a well-known phenomenon observed for a number of protein-small molecule binding systems. As exposed in the preceding section, the $\mathrm{K}_{\mathrm{D}}$ of the hPEBP-FMN complex (Figure 1b) was first determined by applying nonlinear regression analysis on the parameters of Equation (3) to fit to the bound fraction data at 1:1 stoichiometry. A value of $\mathrm{K}_{\mathrm{D}}=54 \mu \mathrm{M}$ was found for the complex. However, the measured bound fraction is skewed by aggregation. Even if GPD is corrected for by using Equation (3), aggregation is not taken into consideration thus far and consequently, an error in the estimation of $\mathrm{K}_{\mathrm{D}}$ potentially remains.

In the course of studying the interaction of hPEBP with another nucleotide, GTP, apparent stoichiometries up to 1:4 were observed when reacting $18 \mu \mathrm{M}$ hPEBP with $500 \mu \mathrm{M}$

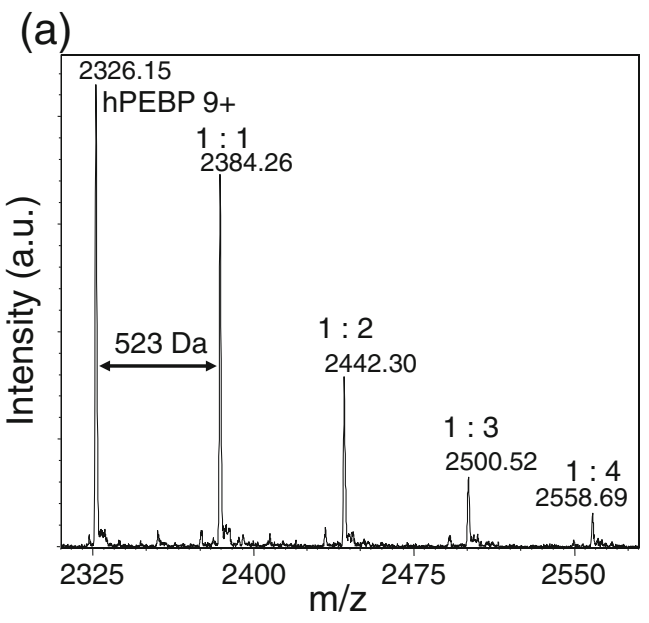

(b)

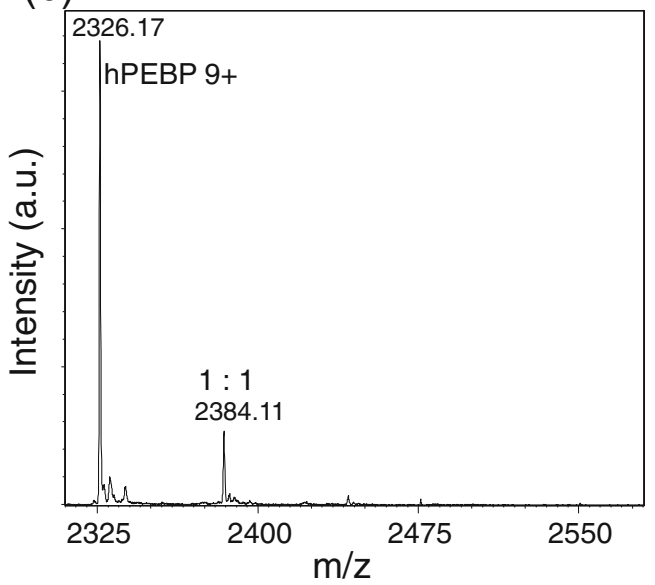

Figure 2. Positive ion native ESI mass spectra (charge state $9+$ ) of $18 \mu \mathrm{M} \mathrm{hPEBP}$ with $500 \mu \mathrm{M}$ GTP (delta-mass $=+523 \mathrm{Da}$ ) following incubation at $37{ }^{\circ} \mathrm{C}$ in $20 \mathrm{mM}$ ammonium bicarbonate, $\mathrm{pH} 8.4$, (a) without micro gel filtration, (b) with micro gel filtration. Peaks are marked with their apparent stoichiometry 
GTP (Figure 2a). The protein peaks distribution is typical of the presence of nonspecific interactions. Nonspecific interactions overlapped with specific interactions make data interpretation more complex, leading to the common strategy of decreasing the ligand concentration to avoid aggregation. This strategy however has an important drawback, in that low affinity complexes may not be observable at such low concentrations. Consequently, we decided to devise an alternative strategy aimed at preventing aggregation.

To this end, while the range of concentrations used was kept high enough to allow for complex measurement, excess free ligand present after incubation of the partners was eliminated by adding a step of micro gel filtration (MGF). After MGF, the apparent binding stoichiometry is down to 1:1 (Figure 2b). This step thus seems efficient at free ligand removal and prevention of aggregation. Adding the MGF step makes it possible to work with a large excess of ligand in the case of low affinity complexes $\left(K_{D} \geq 1 \mu \mathrm{M}\right)$, while eliminating the risk of aggregation due to excess free ligand. This leads to a new experimental flow (Figure 3).

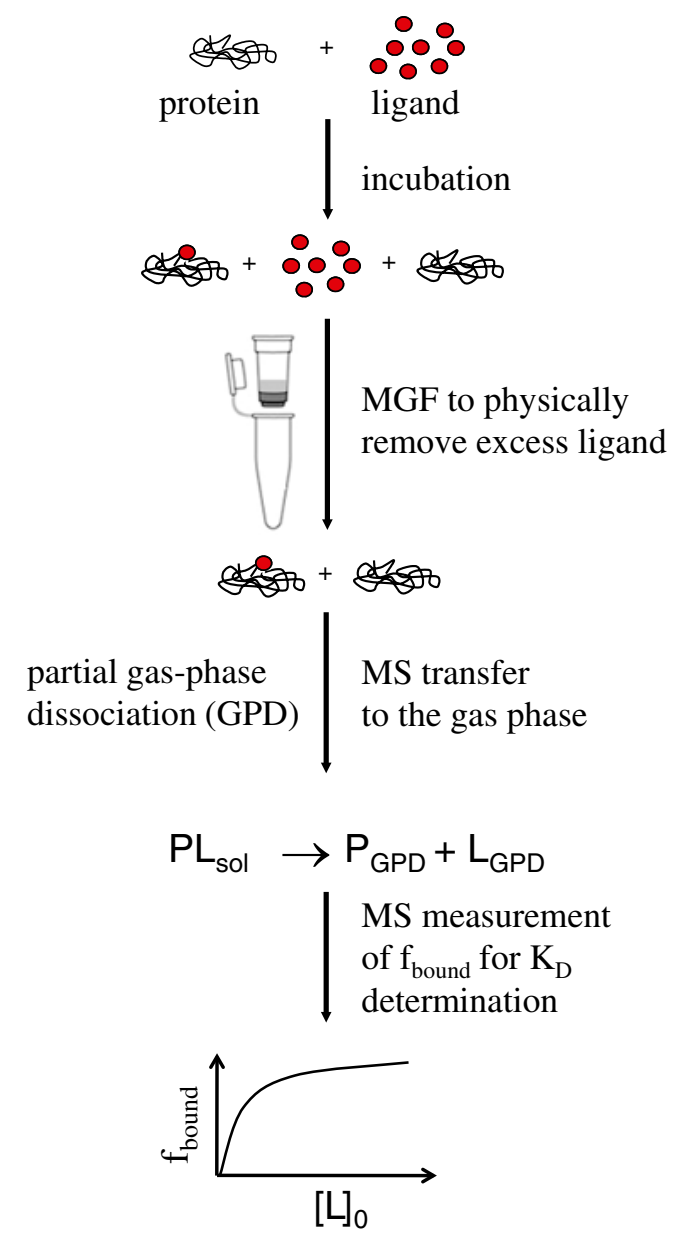

Figure 3. New experimental flow to determine low affinity $\mathrm{K}_{\mathrm{D}}$ by ESI-MS
The main object of this work is to produce a $\mathrm{K}_{\mathrm{D}}$ determination accurately reflecting the solution equilibrium. Both aggregation and GPD can affect $K_{D}$ accuracy. Therefore our approach was designed to deal with both GPD and aggregation in the same experimental workflow and to integrate modeling of the system's behavior according to its kinetics into the approach.

\section{An Integrated Approach and Model to Deal with GPD and Aggregation}

The new experimental flow for the determination of low affinity dissociation constants is presented in Figure 3. Scheme 2 is the general model corresponding to this new experimental flow, where $[\mathrm{P}]_{1},[\mathrm{~L}]_{1}$ and $[\mathrm{PL}]_{1}$ are the protein, ligand, and complex concentrations at equilibrium 1 in solution starting from $[\mathrm{P}]_{0}$ and $[\mathrm{L}]_{0}$ concentrations.

$[\mathrm{P}]_{\mathrm{F}},[\mathrm{L}]_{\mathrm{F}}$, and $[\mathrm{PL}]_{\mathrm{F}}$ are the protein, ligand, and complex concentrations immediately after MGF, $[\mathrm{P}]_{2},[\mathrm{~L}]_{2}$, and $[\mathrm{PL}]_{2}$ are the protein, ligand, and complex concentrations reached when equilibrium is attained by liquid-phase dissociation (LPD) after MGF, $[\mathrm{P}]_{\mathrm{GPD}},[\mathrm{L}]_{\mathrm{GPD}}$ are the protein and ligand concentrations resulting from gas-phase dissociation (GDP), and $[\mathrm{P}]_{\mathrm{M}},[\mathrm{PL}]_{\mathrm{M}}$ are the relative protein and complex concentrations derived from the relative protein and complex peak intensities on the mass spectrum.

Equilibrium 1 is reached in solution after incubation of the protein with the ligand. MGF filtration is then used to eliminate free ligand with recovery of the protein in free or bound form. Equilibrium 2 in solution can be reached if the system follows fast kinetics or if one waits long enough. During MS analysis, the sample is transferred to the gas phase with the risks of dissociation previously exposed. The measurement is performed on the peak intensities for $\mathrm{P}_{\mathrm{M}}$ and $\mathrm{PL}_{\mathrm{M}}$ on the mass spectrum.

The dissociation constant $\mathrm{K}_{\mathrm{D}}$ is the ratio of the dissociation rate constant $\mathrm{k}_{\text {off }}$ to the association rate constant $\mathrm{k}_{\text {on }}$ :

$$
\mathrm{K}_{\mathrm{D}}=\frac{\mathrm{k}_{o f f}}{\mathrm{k}_{o n}}
$$

For low affinity systems, different combinations of $\mathrm{k}_{\text {off }}$ and $\mathrm{k}_{o n}$ values can produce a high $\mathrm{K}_{\mathrm{D}}$ value. The limit cases are a high $\mathrm{k}_{\text {off }}$ with a medium $\mathrm{k}_{\text {on }}$, and a low $\mathrm{k}_{\text {off }}$ with a very low $\mathrm{k}_{\text {on }}$. In the first case, the dissociation to a second equilibrium is very fast because $\mathrm{k}_{\text {off }}$ is high. In contrast, in the second case, the dissociation after MGF is very slow. The following model (Scheme 3) presents the limit cases subsequent to the MGF step.

In Scheme 3, $[\mathrm{P}]_{\mathrm{i}}(\mathrm{t}),[\mathrm{L}]_{\mathrm{i}}(\mathrm{t})$, and $[\mathrm{PL}]_{\mathrm{i}}(\mathrm{t})$ are the protein, ligand and complex concentrations in the intermediary step, respectively, at any given time $\mathrm{t}$ after MGF.

The "fast dissociation" case corresponds to a situation where the complex dissociates very quickly, so that the 


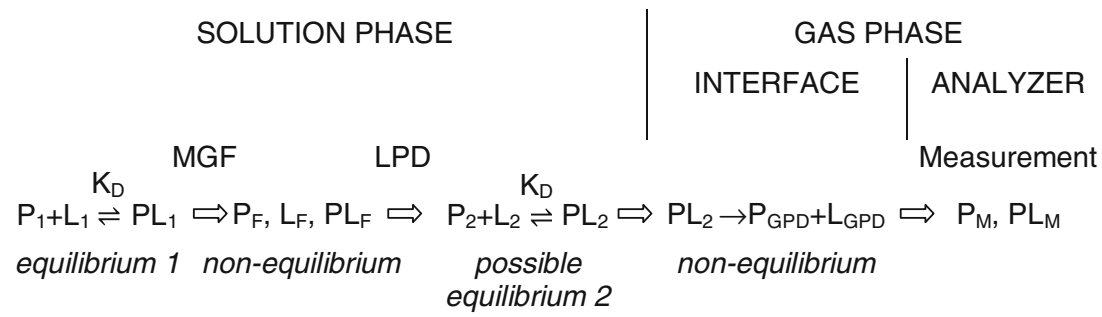

Scheme 2. General model describing system behavior from the solution to the instrument analyzer

system reaches a new equilibrium in the analysis dead-time. In the "no dissociation" case on the other hand, the system has a very low dissociation rate constant, so that the complex does not have enough time to dissociate in any significant way in the analysis dead-time. Mathematical developments for the limit cases are presented below.

\section{"Fast Dissociation" Case}

The equation for $\mathrm{K}_{\mathrm{D}}$ determination with a floating $\mathrm{f}_{\text {sat }}$ is derived from kinetic equations, the equations for mass action law and the law of conservation of mass as well as equations associated with the particular conditions of the experiment, such as MGF as shown in Table 1.

$\mathrm{f}_{\text {bound }}$ is the bound fraction as measured by ESI-MS. The binding of a small ligand with a protein is assumed not to significantly alter the protein ionization and detection efficiencies during MS measurement.

Under this assumption, the intensities in the mass spectrum reflect the relative gas-phase concentrations of the complex and the free protein, so that the $\mathrm{I}(\mathrm{PL})_{\mathrm{M}} / \mathrm{I}(\mathrm{P})_{\mathrm{M} \text { tot }}$ ratio corresponding to $[\mathrm{PL}]_{\mathrm{M}} /[\mathrm{P}]_{\mathrm{M}}$ tot can be calculated by adding the protein peak intensities for PL or for $\mathrm{P}$ at different charge states. The $a$ and $b$ constants represent the fraction of recovery after the MGF step of protein and ligand, respectively. Since the MGF is optimized to recover most of the protein, constant $a$ is close to 1 , whereas constant $b$ is close to 0 if the removal of excess ligand is efficient. During this step, the bound and free protein can be expected to have sufficiently close molecular masses and shapes to behave similarly, so that recovery of the material is identical for both.

Below is the mathematical development used to obtain a direct expression for the determination of the solution $\mathrm{K}_{\mathrm{D}}$ from the mass-measured $f_{\text {bound }}$ ratio:

$$
\mathrm{f}_{\text {bound }}=\frac{[\mathrm{PL}]_{\mathrm{M}}}{[\mathrm{P}]_{\mathrm{M} \text { tot }}}
$$

Using mass conservation equations, we can demonstrate that:

$$
[\mathrm{P}]_{\mathrm{M} \mathrm{tot}}=a[\mathrm{P}]_{0}
$$

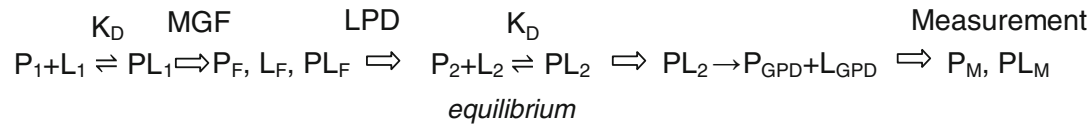

$$
\begin{aligned}
& \text { fast dissociation }
\end{aligned}
$$

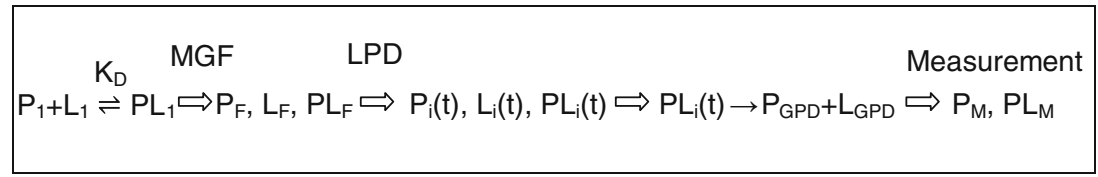

$$
\begin{aligned}
& \sqrt{ } \text { no dissociation } \\
& \mathrm{K}_{\mathrm{D}} \text { MGF non-equilibrium Measurement } \\
& \mathrm{P}_{1}+\mathrm{L}_{1} \rightleftharpoons \mathrm{PL}_{1} \Rightarrow \mathrm{P}_{\mathrm{F}}, \mathrm{L}_{\mathrm{F}}, \mathrm{PL}_{\mathrm{F}} \longrightarrow \mathrm{PL}_{\mathrm{F}} \rightarrow \mathrm{P}_{\mathrm{GPD}}+\mathrm{L}_{\mathrm{GPD}} \Rightarrow \mathrm{P}_{\mathrm{M}}, \mathrm{PL}_{\mathrm{M}}
\end{aligned}
$$

Scheme 3. Limit cases to the general model 
Table 1. Scheme and Equations Relating to the "Fast Dissociation" Case

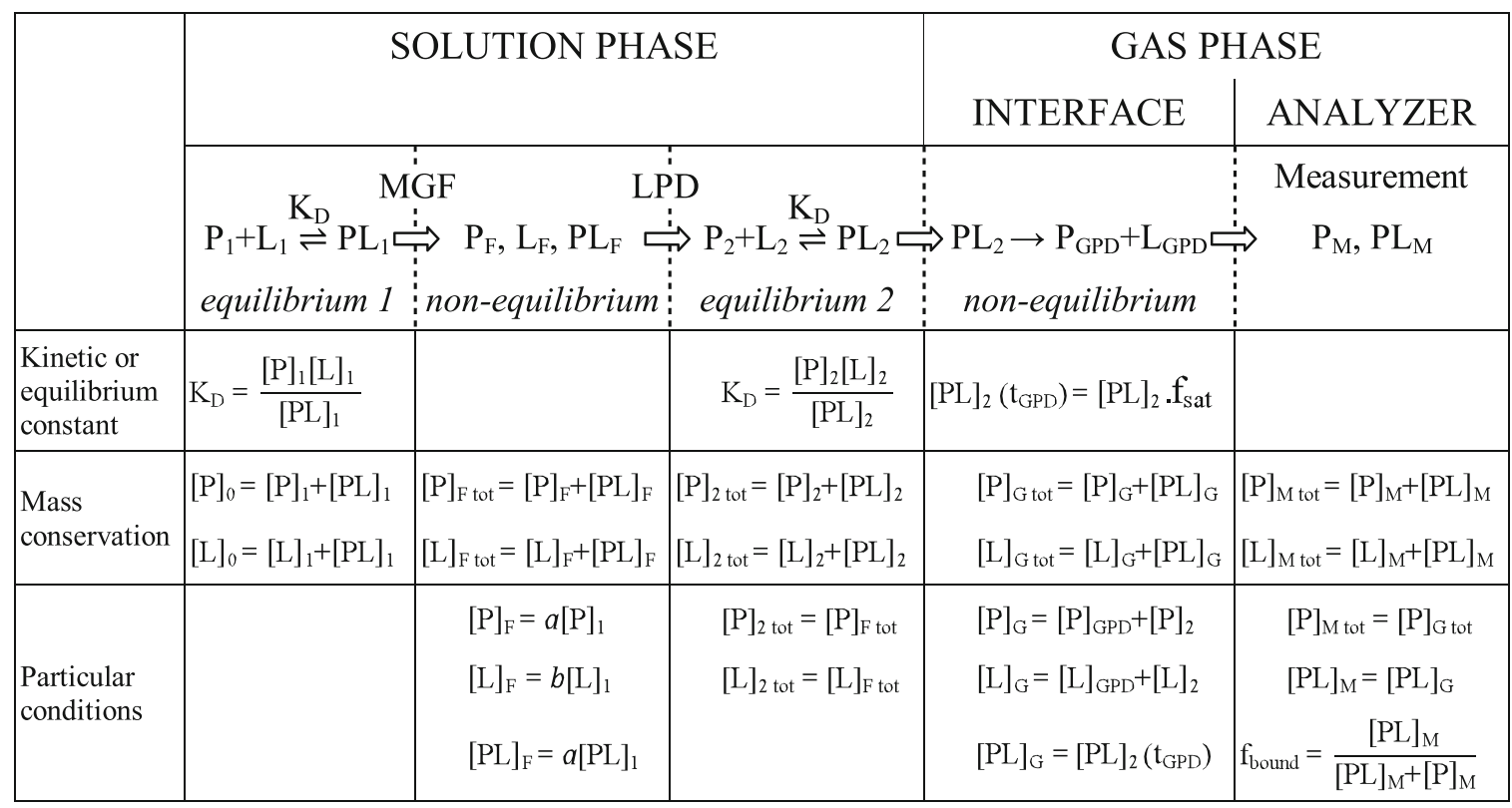

According to equations associated with the particular conditions of the experiment, we know that:

$$
[\mathrm{P}]_{\mathrm{M}}=[\mathrm{PL}]_{2} \cdot \mathrm{f}_{\mathrm{sat}}
$$

The combination of Equations (7), (8), and (9) gives:

$$
\mathrm{f}_{\text {bound }}=\frac{[\mathrm{PL}]_{2} \cdot \mathrm{f}_{\mathrm{sat}}}{a[\mathrm{P}]_{0}}
$$

By combining kinetic equations, the equations for the law of conservation of mass as well as equations associated with the particular conditions of the experiment, $[\mathrm{PL}]_{2}$ can be expressed as a function of $a, b,[\mathrm{P}]_{0},[\mathrm{~L}]_{0}, \mathrm{~K}_{\mathrm{D}}$ and $[\mathrm{PL}]_{1}$ (Equation 11).

If $[\mathrm{PL}]_{1}$ can be expressed as a function of $[\mathrm{P}]_{0},[\mathrm{~L}]_{0}$, and $\mathrm{K}_{\mathrm{D}}$, it will lead to an expression of $[\mathrm{PL}]_{2}$, which only depends on these fixed values. An equation equivalent to the classical quadratic Equation (1) can be used to express $[\mathrm{PL}]_{1}$ (Equation 12).

Combining and reducing Equations (10), (11), and (12) produces the final expression of $\mathrm{f}_{\text {bound }}$ as a function of the fixed $a, b,[\mathrm{P}]_{0}$, and $[\mathrm{L}]_{0}$ values and of the $\mathrm{K}_{\mathrm{D}}$ and $\mathrm{f}_{\mathrm{sat}}$ parameters (Equation 13).

$$
\begin{aligned}
& {[\mathrm{PL}]_{2}=\frac{a[\mathrm{P}]_{0}+b[\mathrm{~L}]_{0}+(a-b)[\mathrm{PL}]_{1}+\mathrm{K}_{\mathrm{D}}-\sqrt{\left(a[\mathrm{P}]_{0}-b[\mathrm{~L}]_{0}-(a-b)[\mathrm{PL}]_{1}-\mathrm{K}_{\mathrm{D}}\right)^{2}+4 a[\mathrm{P}]_{0} \mathrm{~K}_{\mathrm{D}}}}{2}} \\
& {[\mathrm{PL}]_{1}=\frac{[\mathrm{PL}]_{0}+[\mathrm{L}]_{0}+\mathrm{K}_{\mathrm{D}}-\sqrt{\left([\mathrm{P}]_{0}-[\mathrm{L}]_{0}-\mathrm{K}_{\mathrm{D}}\right)^{2}+4[\mathrm{P}]_{0} \mathrm{~K}_{\mathrm{D}}}}{2}} \\
& \left.\begin{array}{rl}
\mathrm{f}_{\text {bound }}=\frac{\mathrm{f}_{\mathrm{sat}}}{2 a[\mathrm{P}]_{0}} \cdot & \frac{}{\frac{3 a-b}{2}[\mathrm{P}]_{0}+\frac{a+b}{2}[\mathrm{~L}]_{0}+\frac{2+a-b}{2} \mathrm{~K}_{\mathrm{D}}-\frac{a-b}{2} \sqrt{\left([\mathrm{P}]_{0}-[\mathrm{L}]_{0}-\mathrm{K}_{\mathrm{D}}\right)^{2}+4[\mathrm{P}]_{0} \mathrm{~K}_{\mathrm{D}}}} \\
& -\sqrt{\left(\frac{a+b}{2}[\mathrm{P}]_{0}-\frac{a+b}{2}[\mathrm{~L}]_{0}-\frac{2+a-b}{2} \mathrm{~K}_{\mathrm{D}}+\frac{a-b}{2} \sqrt{\left([\mathrm{P}]_{0}-[\mathrm{L}]_{0}-\mathrm{K}_{\mathrm{D}}\right)^{2}+4[\mathrm{P}]_{0} \mathrm{~K}_{\mathrm{D}}}\right)^{2}+4 a[\mathrm{P}]_{0} \mathrm{~K}_{\mathrm{D}}}
\end{array}\right)
\end{aligned}
$$


In the "fast dissociation" case, nonlinear regression with Equation (13) gives direct access to the $\mathrm{K}_{\mathrm{D}}$ in solution and to the $\mathrm{f}_{\text {sat }}$ linked to MS measurement of the studied system.

\section{"No Dissociation" Case}

The mathematical development for the "no dissociation" case (Table S1) is simplified by the fact that there is no re-equilibration in solution after MGF. The beginning of the mathematical demonstration is similar to the "fast dissociation" case.

In the "no dissociation" case, the equivalent to Equation (10) is Equation (14). We know that $f_{\text {bound }}$ can be expressed as a function of $a,[P]_{0},[P]_{0}$, and $\mathrm{f}_{\text {sat }}$ by inserting Equation (12) into Equation (15), and inserting the final expression in Equation (14) to give Equation (16):

$$
\mathrm{f}_{\text {bound }}=\frac{[\mathrm{PL}]_{\mathrm{F}} \cdot \mathrm{f}_{\mathrm{sat}}}{a[\mathrm{P}]_{0}}
$$

We know that $[\mathrm{PL}]_{\mathrm{F}}=a[\mathrm{PL}]_{1}$

$\mathrm{f}_{\text {bound }}=\mathrm{f}_{\text {sat }} \cdot \frac{[\mathrm{P}]_{0}+[\mathrm{L}]_{0}+\mathrm{K}_{\mathrm{D}}-\sqrt{\left([\mathrm{P}]_{0}+[\mathrm{L}]_{0}+\mathrm{K}_{\mathrm{D}}\right)^{2}-4[\mathrm{P}]_{0}[\mathrm{~L}]_{0}}}{2[\mathrm{P}]_{0}}$

Equation (16) is identical to Equation (3) found in the first section, meaning that the introduction of a MGF step for a non-dissociating complex does not alter the final mathematical expression for solution $\mathrm{K}_{\mathrm{D}}$ measurement.

In the "no dissociation" case, the complex in solution stays intact after the MGF step. This means that this type of system is ideal for working with the large excess of ligand necessary for low affinity systems, and takes full advantage of the MGF step to prevent aggregation.

On the other hand, in the "fast dissociation" case, a second equilibrium in solution is reached following the MGF, so that the elimination of aggregation afforded by MGF does not translate into an effective increase in the measured bound fraction. In other words, this limit case corresponds to a situation where the measured species are equivalent to what would be observed directly with a lower gamut of ligand concentrations for which there is no aggregation. There are however practical advantages to applying MGF and Equation (13) to such a system. First, this approach does not necessitate a priori knowledge on the system and the mathematical treatment relies on the occurrence of two instances of the solution $\mathrm{K}_{\mathrm{D}}$ corresponding to equilibriums 1 and 2, which gives the determination internal consistency. Second, the protein-ligand complex is usually formed in a physiologically relevant buffer which may need to be buffer-exchanged before the MS analysis. Finally, the initial complex formation step will proceed faster at the high ligand concentrations allowed with an MGF step. This may be valuable for proteins and/or ligands with limited stability. In other cases with fast dissociating complexes where it is experimentally feasible to skip the MGF step and to decrease the ligand concentration, Equation (3) can be applied directly for $\mathrm{K}_{\mathrm{D}}$ determination.

\section{"Partial Dissociation" Case}

Between the two limit cases presented above, "partial dissociation," corresponding to an intermediary case, occurs. Mathematical development for this case was attempted and is presented in Supplementary Materials. This leads to the fairly complex Equation S14, which contains four remaining unknowns. Attempts at fitting this increased number of parameters would lead to a greater freedom for nonlinear regression to find compatible sets of parameter solutions, so as to render the result potentially meaningless.

Thus, it is more useful to examine conditions for which any low affinity system can be brought to behave according to one of the two limit cases. The next section provides general guidelines for setting up the $K_{D}$ determination experiments. For a fine tuning of experimental conditions,

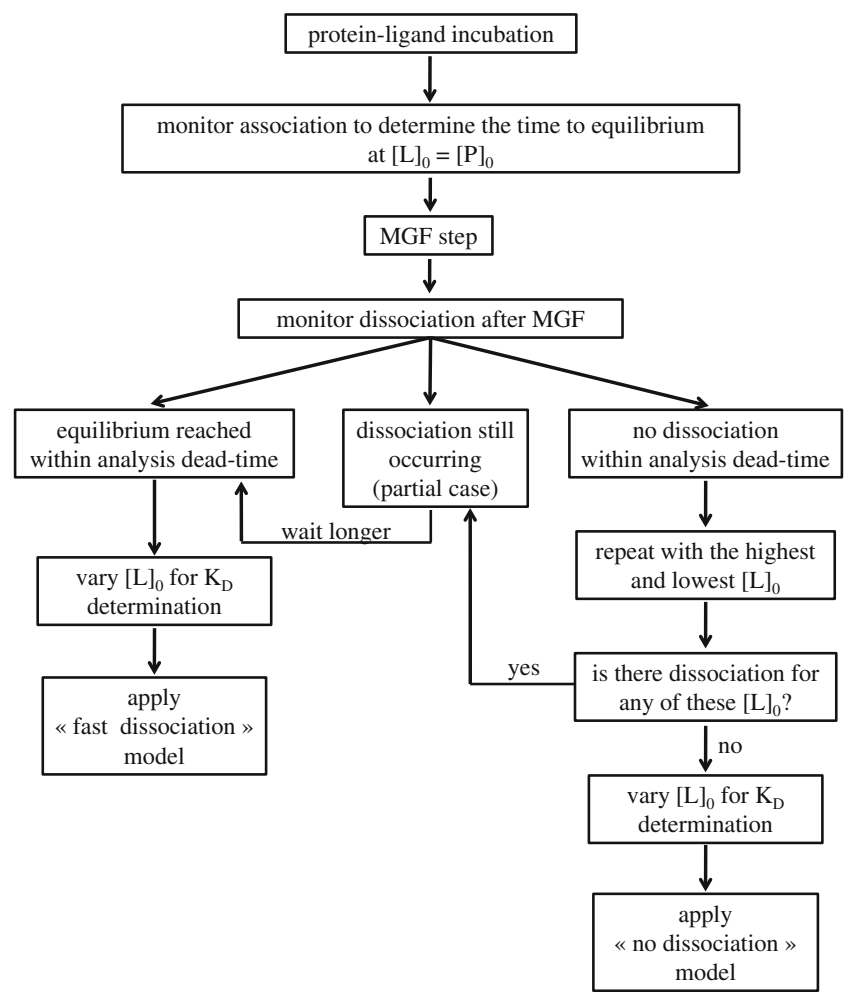

Figure 4. Experimental decision tree to aid in $\mathrm{K}_{\mathrm{D}}$ determination by ESI-MS 
graphs simulating the system's kinetic behavior according to theoretical rate and equilibrium constants (Figures S1 and S2) can be used. The equations for building such simulations for a given set of initial conditions are provided in Supplementary Materials.

\section{Guidelines to Determine which Model to Apply}

In practical situations, the $\mathrm{K}_{\mathrm{D}}$ is usually unknown, with at best an order of magnitude guesstimate for its value. The same can be said for the $\mathrm{k}_{\text {on }}$ and $\mathrm{k}_{\text {off }}$ values. Some preliminary information is thus necessary to ensure that low affinity $K_{D}$ constants are measured in a safe way with the right model applied. The experimental decision tree (Figure 4) shows a strategy to gather preliminary information and to select the model to apply. The first step consists in determining a safe incubation time to ensure that complexes in solution are studied at equilibrium. This should be done at the 1:1 protein:ligand stoichiometric point where the longest association times occur, as shown by a plot of the association behavior of binding systems (Figure S1). The next step consists in applying MGF and determining which case the studied system falls into. This is done by simply monitoring dissociation post-MGF over a few time points. If dissociation is still occurring after the analysis dead-time, the studied system falls into the "partial dissociation" case. The system can be then brought back to the "fast dissociation" case by allowing it to re-equilibrate for a longer period of time after MGF. Alternatively, a system's behavior can be manipulated to reach one of the limit cases by playing on the range of initial ligand concentrations. This approach requires a finer understanding of the effect of ligand concentrations on kinetic behavior, and is described in Supplementary Materials along with simulation tools to assist in experimental choices. Once it is ensured that the studied system falls either into the "fast dissociation" or the "no dissociation" case, $\mathrm{K}_{\mathrm{D}}$ determination can be performed by varying the ligand concentration and applying the appropriate model.

\section{Application to hPEBP-GTP}

As shown above, this system is sensitive to aggregation. Preliminary monitoring of association kinetics of $18 \mu \mathrm{M}$ hPEBP with a ligand concentration close to the protein concentration and with a high GTP concentration (36 and $500 \mu \mathrm{M}$, respectively) was conducted to determine a safe incubation time. The equilibrium is reached in less than 2 min (data not shown). To figure out which model applies to this system, dissociation kinetics was monitored after a MGF step following $8 \mathrm{~min}$ of incubation in the above conditions (Figure 5a). The complex dissociates very fast in solution, so that in less than $180 \mathrm{~s}$, a new equilibrium has already been reached. Consequently, the hPEBP-GTP complex follows the "fast dissociation" model. Applying nonlinear regression analysis with Equation (13) on hPEBP-
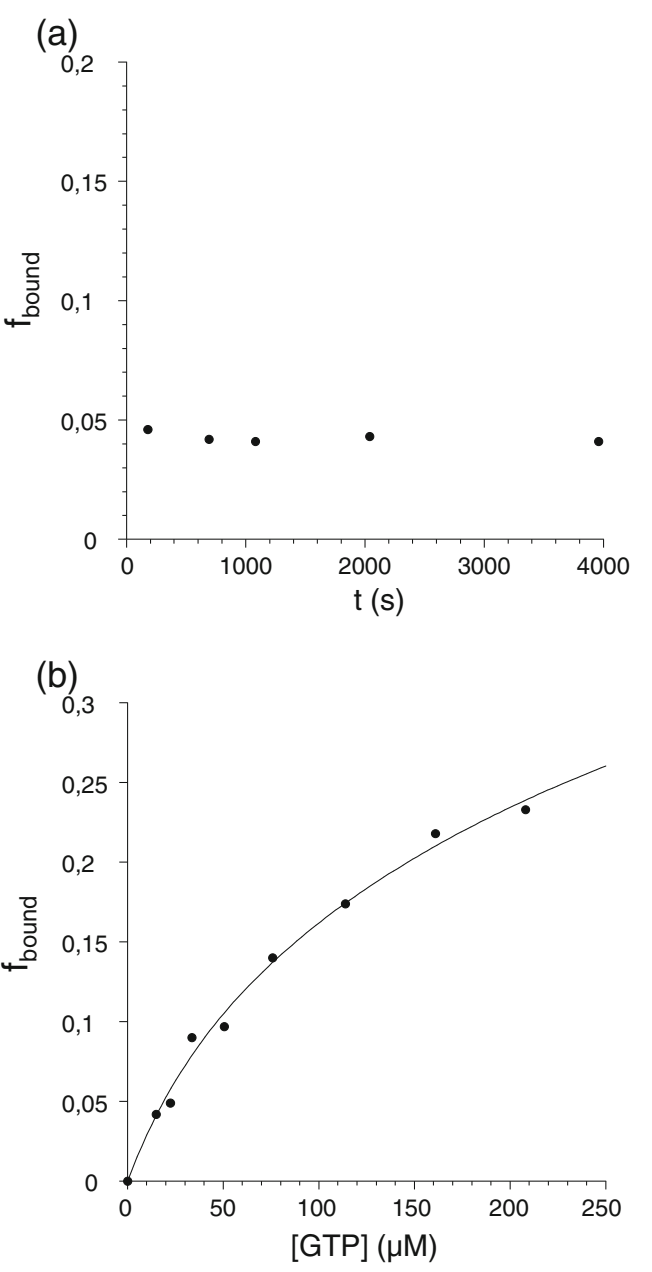

Figure 5. (a) MS-measured bound hPEBP fraction as a function of time after micro gel filtration. The complex formed by incubating $18 \mu \mathrm{M}$ hPEBP with $36 \mu \mathrm{M}$ GTP at $37^{\circ} \mathrm{C}$ in $20 \mathrm{mM}$ ABC, pH 8.4, was micropurified using Zeba microspin columns. The time to reach $95 \%$ dissociation is below $180 \mathrm{~s}$. (b) MS-measured hPEBP bound fraction as a function of ligand concentration after micro gel filtration. The complex was formed by incubating $18 \mu \mathrm{M}$ PEBP with 0-208 $\mu \mathrm{M}$ GTP at $37^{\circ} \mathrm{C}$ in $20 \mathrm{mM} \mathrm{ABC}, \mathrm{pH}$ 8.4. The $\mathrm{K}_{\mathrm{D}}$ and $\mathrm{f}_{\text {sat }}$ parameters of Equation (13) were fitted by nonlinear regression analysis to the data

GTP $\mathrm{f}_{\text {bound }}$ data gives a very good fit (Figure $5 b$ ) with $\mathrm{R}^{2}=0.99$, $\mathrm{K}_{\mathrm{D}}=40 \pm 1.0 \mu \mathrm{M}$ and $\mathrm{f}_{\text {sat }}=0,52$.

Since hPEBP and GTP are stable over time and the incubation buffer in this instance is compatible with native mass spectrometry, one can choose to skip the MGF step to determine $\mathrm{K}_{\mathrm{D}}$. In this case, the ligand concentration must be decreased to avoid aggregation. To this end, a range of ligand concentrations was screened to determine the highest point for which, in the absence of MGF, no stoichiometries above 1:1 are observed. Since the longest association times occur around the protein:ligand stoichiometric point, the association time in these conditions was confirmed to be below $2 \mathrm{~min}$. In the case of the hPEBP-GTP complex, the fit using Equation (3) is very good with $\mathrm{R}^{2}=0.99$ and gives 
Table 2. $\mathrm{K}_{\mathrm{D}}$ Constants Determined Through MS Measurement with and without $\mathrm{f}_{\mathrm{sat}}$ Correction versus $\mathrm{K}_{\mathrm{D}}$ Constants Determined by In-solution Methods

\begin{tabular}{|c|c|c|c|c|c|c|c|}
\hline \multirow[t]{2}{*}{ P-L complex } & \multirow[t]{2}{*}{ Experimental conditions } & \multicolumn{2}{|c|}{$\begin{array}{l}\mathrm{K}_{\mathrm{D}} \text { measurement without GPD } \\
\text { correction (Equation (1)) }\end{array}$} & \multicolumn{3}{|c|}{$\begin{array}{c}\mathrm{K}_{\mathrm{D}} \text { measurement with GPD } \\
\text { correction (Equations (3) or (13)) }\end{array}$} & \multirow[t]{2}{*}{ Literature $\mathrm{K}_{\mathrm{D}}(\mu \mathrm{M})$} \\
\hline & & $K_{D}(\mu M)$ & $R^{2}$ & $K_{D}(\mu M)$ & $f_{\text {sat }}$ & $R^{2}$ & \\
\hline RNase-CTP & $10 \mathrm{mM} \mathrm{NH}_{4} \mathrm{OAc}, \mathrm{pH} 6.8 ; 25^{\circ} \mathrm{C}$ & $17 \pm 1.4$ & 0.911 & $1.6 \pm 0.24$ & $0.47 \pm 0.07$ & 0.971 & $0.7[31] ; 0.5-2^{\mathrm{a}}[32-34]$ \\
\hline PEBP-P3P & $20 \mathrm{mM} \mathrm{ABC}, \mathrm{pH} 7.4 ; 25^{\circ} \mathrm{C}$ & $160 \pm 15$ & 0.927 & $11 \pm 0.74$ & $0.26 \pm 0.02$ & 0.995 & $20[35]$ \\
\hline HEWL-NAG3 & $50 \mathrm{mM} \mathrm{NH}_{4} \mathrm{OAc}, \mathrm{pH} 6.6 ; 37^{\circ} \mathrm{C}$ & $19 \pm 1.2$ & 0.993 & $20 \pm 1.2$ & $1.02 \pm 0.08$ & 0.993 & $8.6[36]$ \\
\hline$(\mathrm{CK})_{2}-2 \mathrm{ADP}$ & $\begin{array}{l}10 \mathrm{mM} \mathrm{ABC}, \mathrm{pH} 7.9 ; 37^{\circ} \mathrm{C} \\
\text { ESI-UHRQ-TOF }\end{array}$ & $15 \pm 1.2$ & 0.951 & $4.5 \pm 0.54$ & $0.61 \pm 0.17$ & 0.964 & $24[16]-33^{\text {b }} ; 40[37]$ \\
\hline PEBP-GTP & $20 \mathrm{mM} \mathrm{ABC}, \mathrm{pH} 8.4 ; 37^{\circ} \mathrm{C}$ & $140 \pm 6.7$ & 0.984 & $36 \pm 0.62$ & $0.42 \pm 0.03$ & 0.999 & n.d. \\
\hline PEBP-GTP & $20 \mathrm{mM} \mathrm{ABC}, \mathrm{pH} 8.4 ; 37^{\circ} \mathrm{C}+\mathrm{MGF}$ & $230 \pm 26$ & 0.896 & $55 \pm 5.0$ & $0.40 \pm 0.07$ & 0.970 & n.d. \\
\hline PEBP-GTP & $\begin{array}{l}20 \mathrm{mM} \mathrm{ABC}, \mathrm{pH} 8.4 ; 37^{\circ} \mathrm{C}+\mathrm{MGF}, \\
\text { ESI-UHRQ-TOF }\end{array}$ & $98 \pm 4.6$ & 0.962 & $40 \pm 1.0$ & $0.52 \pm 0.05$ & 0.993 & n.d. \\
\hline PEBP-FMN & $20 \mathrm{mM} \mathrm{ABC}, \mathrm{pH} 8.4 ; 37^{\circ} \mathrm{C}+\mathrm{MGF}$ & $240 \pm 28$ & 0.854 & $35 \pm 3.1$ & $0.25 \pm 0.05$ & 0.967 & n.d. \\
\hline
\end{tabular}

Unless otherwise stated, an ESI-IT instrument was used.

[31] MS, Zhang et al. 2003; [32] ITC, Straume et al. 1992; [33] DSC, Wiseman et al. 1989; [34] CD, Jones et al. 2002; [35] SPR, Park et al. 2006; [36] fluorescence, Schindler et al. 1977; [16] MS, Daubenfeld et al., 2006, [37] ligand radio-labeling, Burbaum et al. 1989.

For PEBP-nucleotide complexes, there is no reference $\mathrm{K}_{\mathrm{D}}$ in solution. However, the measured $\mathrm{K}_{\mathrm{D}}$ values rank the same as previously determined ranking of affinities.

Errors are standard errors of fitting. For the sake of comparison with errors on $K_{D}$ determined using Equation (1), errors on $K_{D}$ with $f_{\text {sat }}$ correction (Equation (3) or (13)) were calculated by a second round of regression analysis using the determined $\mathrm{f}_{\text {sat }}$ as a fixed parameter.

$\mathrm{MS}=$ mass spectrometry; ITC=isothermal titration calorimetry; $\mathrm{DSC}=$ differential scanning calorimetry; $\mathrm{CD}=$ circular dichroism; $\mathrm{SPR}=$ surface plasmon resonance; $\mathrm{NMR}=$ nuclear magnetic resonance; n.d. $=$ not determined

${ }^{a}$ Value for 2'-CMP.

${ }^{b}$ Recomputed $\mathrm{K}_{\mathrm{D}}$, taking into account free protein in peaks of apparent stoichiometry $>1$, as modeled by the authors.

$\mathrm{K}_{\mathrm{D}}=36 \pm 0.62 \mu \mathrm{M}$ with $\mathrm{f}_{\text {sat }}=0.42$ (data not shown). The similarity of these values with values obtained at higher ligand concentrations with a MGF step confirms that the new experimental protocol is efficient for preventing aggregation.

With the right tools in hand to deal with aggregation and the effect of its remedy on kinetic behavior, the model can be validated from the point of view of the GPD correction by applying this approach to other systems.

\section{Comparison of $K_{D}$ Values Determined Using GPD Correction with $K_{D}$ Values Determined in Solution}

To validate the model, the accuracy of the GPD correction and the correlation of the MS-measured equilibrium dissociation constants $\mathrm{K}_{\mathrm{D}}$ with literature $\mathrm{K}_{\mathrm{D}}$ values were evaluated. The degree of data correlation when performing regression analysis using theoretical Equation (1), which does not take GPD into account, was contrasted with the result obtained using Equation (3), which corrects for GPD (Table 2).

The comparison was made for six systems: RNase-CTP, PEBP-P3P, HEWL-NAG3, $(\mathrm{CK})_{2}$-2ADP, PEBP-FMN, and PEBP-GTP. The correlation coefficient is generally greater with Equation (3) than with Equation (1). Moreover, with Equation (3) the correlation coefficient is improved to a higher extent for complexes which present a low stability in the gas phase, as measured by a low $\mathrm{f}_{\text {sat. }}$. For these complexes, the dissociation constant can vary by as much as a factor of 10 as a consequence of substituting Equation (3) for Equation (1) in the regression analysis. For complexes with a higher resistance to GPD such as HEWL-NAG3, a very minor correction for GDP is required, and accordingly the difference between a determination with and without GPD correction is significantly smaller. The improvement in correlation coefficients when
GPD correction is applied suggests that the MS bound fraction indeed reflects both solution binding and a phenomenon of GPD, thus confirming the necessity to include this correction in model building.

The MS-measured $K_{D}$ computed with Equation (3) was then compared with the literature values found for $K_{D}$ determined by various methods based on the analysis of complexes in solution (Table 2). The comparison was made for four reference systems: RNase-CTP, PEBP-P3P, HEWL$\mathrm{NAG} 3$, and $(\mathrm{CK})_{2}$-2ADP. In the literature, $\mathrm{K}_{\mathrm{D}}$ values have been determined by various methods in solution (ITC, DSC, $\mathrm{CD}$, SPR, fluorescence or ligand radio-labeling). Solutionmeasured $\mathrm{K}_{\mathrm{D}}$ values of 0.5 to $1.6 \mu \mathrm{M}$ can be found in the literature for the RNase-CMP system [32-34]. These were found to be close to that of RNase-CTP as determined by another MS study [31]. As 2'CMP was unobtainable worldwide, our method was applied to the RNase-CTP system. The MS measured $\mathrm{K}_{\mathrm{D}}$ value computed with Equation (3) is again closer to the literature values than the one computed with Equation (1). The same observation can be made for the PEBP-P3P system. For the HEWL-NAG3 complex, the MS-measured $\mathrm{K}_{\mathrm{D}}$ values computed with Equation (3) or (1) are nearly identical and both are close to the literature value. We can thus conclude that HEWLNAG3 is resistant to GPD and can be considered as a reference for GPD. Last, $(\mathrm{CK})_{2}-2 \mathrm{ADP}$, is a dimer with one binding site per monomer. Again in this case, the $\mathrm{K}_{\mathrm{D}}$ value found with Equation (3) is lower than that found with Equation (1). Both are however lower than the $K_{D}$ measured by in-solution method. Van der Rest and coauthors studied this complex by MS and succeeded in discriminating the aggregation phenomenon from specific interactions using a statistical approach [16]. An average $K_{D}$ value of $24 \mu \mathrm{M}$ for the two 
independent binding sites was reported, in keeping with the literature [16]. A $K_{D}$ value of $33 \mu \mathrm{M}$ can be found by recomputing the data to take free protein in peaks of higher apparent stoichiometry, as modeled by the authors, into account. For this system a $K_{D}$ value of $5 \mu \mathrm{M}$ was found with Equations (3) and $15 \mu \mathrm{M}$ with Equation (1). A $\mathrm{f}_{\text {sat }}$ value of 0.61 suggests a significant level of GPD. If GPD also occurred during the Daubenfeld/van der Rest MS analysis, it could lead to an overestimation of the $\mathrm{K}_{\mathrm{D}}$ value, which could explain the observed difference. On the whole, the comparison of the MS measured $K_{D}$ values with literature data validates the use of our GPD model to determine a $\mathrm{K}_{\mathrm{D}}$ closer to the reality of solution equilibria.

We chose to calculate a weighted average over all charge states to determine $K_{D}$. However, to study the effect of the charge state on the $\mathrm{K}_{\mathrm{D}}$, we also determined $\mathrm{K}_{\mathrm{D}}$ based on individual charge state data (Table S3, Supplementary Materials). In a majority of cases, the best fit is obtained with the major charge state, while being close to the fit obtained with the weighted average. Surprisingly, the weighted average sometimes gives a better fit than any of the individual charge states. The six studied systems do not seem to show a unique trend of $\mathrm{K}_{\mathrm{D}}$-charge state correlation. Until a better understanding of charge state effects is gained, it seems that the use of weighted average data is a reasonable choice.

To calculate binding fractions, we assumed that binding of a small ligand with the target protein does not significantly alter the protein ionization and detection efficiencies during MS measurement. This seems to be the case for the ligands studied in this work. The delta mass observed upon ligand binding corresponds to the mass of a globally neutral molecule. Nucleotides possess two ionic groups of opposite charge and behave as zwitterions. At the near-neutral $\mathrm{pH}$ used in these MS measurements, they may have an overall net charge of zero, so that binding to the protein does not directly alter its charge state. If not, it would have led to a significant shift in the charge state distribution, which was not observed. Moreover, these ligands are relatively small compared to the target protein.

For massive ligands, or for ligands that behave as strictly ionic molecules at the $\mathrm{pH}$ of measurement, such as ionic detergents or metal ions, this assumption may not hold, potentially leading to effects on the complex ionization and detection efficiency. In such cases, the $\mathrm{f}_{\mathrm{sat}}$ correcting factor would compensate for the effects.

Several methods have been developed in recent years to deal with aggregation or GPD. They have in common the use of a reference protein or ligand. One such strategy is based on half-maximal inhibitory concentration (IC50) measurements in a competitive assay with a non-aggregating ligand [18]. IC50 values determined by MS are then converted into $\mathrm{K}_{\mathrm{D}}$. The main disadvantage of this method is the need for a reference ligand. In addition, the reference ligand has to meet the double condition of not forming aggregates with the protein, and having a known solution $\mathrm{K}_{\mathrm{D}}$ [18]. Nonspecific binding of charged biomolecules is a statistical process, independent of protein structure and size [38]. This observation has led to the development of a method using a reference protein to quantify aggregation $[16,38]$. However, the stability of nonspecific complexes is sensitive to the nature of the protein ions. Consequently, the reference protein method for correcting aggregation can only be applied provided that GPD of nonspecific complexes is minimized. In the presence of GPD, this method cannot be applied.

There are two existing methods using a reference ligand for quantifying the affinity of protein-ligand complex that are prone to GPD [23, 39]. The reference ligand has to bind with a known affinity and at the same binding site as the ligand of interest. The reference ligand method is based on the MS measurement of the reference complex in a competitive assay with the ligand of interest. In addition, one of the methods requires that the reference ligand is not prone to GPD [39].

The necessity to have a reference ligand or protein is very restrictive, particularly for exploratory projects where little may be known beforehand about the protein binding site. In addition, none of the above methods takes into account both GPD and aggregation. In contrast, the approach described in this work has the advantage not to require a reference protein or ligand. The presence of GPD can easily be checked and resolved, regardless of the type of complex and aggregation controlled upstream of MS analysis.

\section{Effect of the Type of Noncovalent Interaction on Gas-Phase Dissociation}

Considerations on the effect of the type of molecular interaction in the complex provide a first step in the dissection of the $\mathrm{f}_{\mathrm{sat}}$ parameter. Going from solution to a solventless gas phase environment can alter the strength of noncovalent interactions. Ionic interactions and hydrogen bonds can be strengthened, while the hydrophobic effect is for the most part not conserved [40, 41]. If we consider that the bound fraction measured by MS is a vestige of the complex in solution, that is to say that we measure the ratio of complex that has survived the transfer into the analyzer, then it is reasonable to consider the influence of the type of interactions on the GPD for a given system. To explore this aspect, we can compare the $\mathrm{f}_{\text {sat }}$ results obtained for the HEWL-NAG3 and the hPEBP-P3P systems.

HEWL-NAG3 is an interaction based on hydrogen bonds with hydrophobic contacts $[42,43]$. P3P is a triphosphorylated peptide from Rafl, which has been synthesized and used to obtain information on the hPEBP-Raf1 interaction by studying the hPEBP-P3P complex [35]. The hPEBP-P3P interaction can be surmised to be at least partially based on ionic interactions between amino acid residues and the phosphate groups of the triphosphorylated peptide.

While HEWL-NAG3 (Figure 6a) and hPEBP-P3P (Figure 6b) have similar equilibrium dissociation constants, they have radically different $f_{\text {sat }}$ (Table 2 ). The bound 

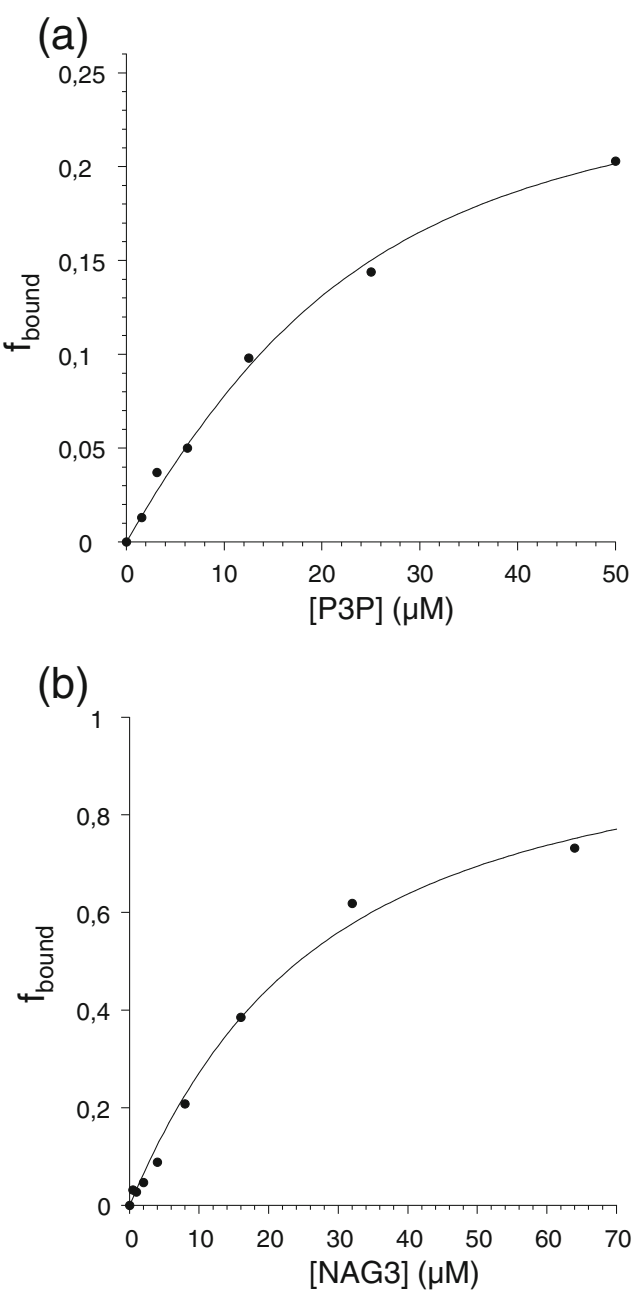

Figure 6. GPD behavior comparison: MS-measured bound protein fraction as a function of ligand concentration. (a) hPEBP $(18 \mu \mathrm{M})$ incubated with 0-50 $\mu \mathrm{M}$ P3P in $20 \mathrm{mM} \mathrm{ABC}$, $\mathrm{pH} 7.4$, at $25^{\circ} \mathrm{C}$. (b) HEWL $(10 \mu \mathrm{M})$ incubated with 0-64 $\mu \mathrm{M}$ NAG3 in $50 \mathrm{mM} \mathrm{NH}_{4} \mathrm{OAc}, \mathrm{pH} 6.6$, at $37^{\circ} \mathrm{C}$. The $\mathrm{K}_{\mathrm{D}}$ and $\mathrm{f}_{\text {sat }}$ parameters of Equation (3) were fitted to the data by nonlinear regression analysis

fraction at saturation for HEWL-NAG3 was determined by nonlinear regression analysis to be 1.02 . This means that there is apparently no discernible dissociation in the gas phase in the course of the analysis. If so, our model successfully handles this system by retrieving an $f_{\text {sat }}$ value that conforms to reality. In cases where an $\mathrm{f}_{\text {sat }}$ value close to 1 is found, regression can be repeated with a fixed parameter value $\mathrm{f}_{\mathrm{sat}}=1$, in other words the classical equation (Equation (1)) can be applied. The hPEBP-P3P complex, on the other hand, reaches a bound fraction of 0.26 at saturation, which means only $26 \%$ of the solution complex survives during the MS analysis. The corrective equation (Equation (3)) must be applied here to take into account the GPD of the complex and thus avoid an overestimation of $\mathrm{K}_{\mathrm{D}}$.

In view of the $f_{\text {sat }}$ value found for HEWL-NAG3, the hypothesis that hydrogen bonds are sufficient to maintain the complex intact during the solution-gas phase transition is plausible. The hPEBP-P3P complex on the other hand largely dissociates in the gas phase, implying that ionic interactions and hydrogen bonds are not major contributors to the binding and that positional sequence-dependent interactions relying on the hydrophobic effect play an important part in complex formation. This aspect could be further explored from a statistical point of view by examining a large number of known systems for which information on the type of interactions is available.

\section{Effect of the Instrument on the Gas-Phase Dissociation}

A consideration of the parameters affecting GPD also calls attention to the influence of the instrumental setup on the dissociation. In particular, the interface pressure and the cone voltage are likely contributors. To test the effect of the instrument on gas-phase dissociation, we determined the equilibrium dissociation constant of hPEBP-GTP using an ESI-IT (HCT Ultra PTM Discovery, Bruker) and an ESIUHR-Qq-TOF (maXis, Bruker). Equilibrium dissociation constants determined by ESI-IT MS and ESI-UHR-Qq-TOF MS are within each other's margin of measurement error (Table 2). However, the complex is somewhat more labile in the ESI-IT mass spectrometer, with $\mathrm{f}_{\mathrm{sat}}=0.42$, than in the ESI-UHR-Qq-TOF $\left(f_{\text {sat }}=0.52\right)$. The interface pressure could be a factor in the dissociation in the interface as a higher pressure favors complex stability $[19,20]$. However, interface pressure is actually higher for ESI-IT than for ESI-UHR-Qq-TOF with values of 6.5 versus 3.5 mbar. Consequently, this parameter cannot explain a higher dissociation in ESI-IT. More likely, differences in energetics linked to the transmission time and voltages may explain the small difference in the percentage of GPD. The equilibrium dissociation constants with GDP correction are close, suggesting that the $\mathrm{f}_{\text {sat }}$ parameter compensates for the level of GPD regardless of the instrument and that consequently, the methodology can be applied independently of instrument choice.

The dissection of the $f_{\text {sat }}$ parameter with respect to the instrumental setup should be further explored. The effect of various instrument parameters on ion energetics and their subsequent impact on dissociation events opens up the possibility of perfecting our understanding of the GPD phenomenon. The knowledge gained would provide a basis for the design of mass spectrometers geared towards preserving noncovalent interactions. Moreover, a precise physical description of GPD could lead to a predictive model for binding system behavior.

\section{Conclusion}

The present work describes a comprehensive approach dealing with both GPD and aggregation in order to determine a $\mathrm{K}_{\mathrm{D}}$ constant that accurately reflects solution binding. The method gives access to a reliable $K_{D}$ by ESI- 
MS without requiring reference ligands or proteins, or preliminary knowledge on the tendency of the system to form aggregates or to dissociate in the gas phase. We introduce the GPD correction factor $\mathrm{f}_{\text {sat }}$, which corresponds to the experimental bound fraction at saturation. The system is freed from aggregation by adding a micro-gel filtration step (MGF) to remove excess ligand after incubation of the ligand-protein. The behavior of the complex is modeled according to its kinetics, allowing for the mathematical development of the corresponding binding equations. The introduction of a MGF step has consequences for the accurate measurement of $\mathrm{K}_{\mathrm{D}}$, which leads to specific recommendations for the application of this type of methods.

The $\mathrm{f}_{\text {sat }}$ constant reflects the type of interaction in the protein-ligand complex, bringing insight into the nature of the complex. $f_{\text {sat }}$ also provides a way to quantitatively measure the ability of an instrument to preserve noncovalent interactions. This work opens up perspectives for a fine dissection of $\mathrm{f}_{\text {sat }}$ to help in the design of mass spectrometers specialized in native MS analysis or to gain insight into the nature of noncovalent complexes.

\section{Acknowledgments}

The authors thank Ludivine Errien for technical assistance with the expression and purification of human PEBP, as well as Drs. Laurette Tavel and Christian Damblon for the kind gift of ${ }^{15} \mathrm{~N}$ labeled human PEBP. Support by the ANR through the award of a "Programme Blanc" grant, and funding by the Ligue Nationale contre le Cancer and the Cancéropôle Grand-Ouest are gratefully acknowledged. L.J. benefited from Ph.D. funding by CNRS and Région Centre.

\section{References}

1. Ganem, B., Li, Y.T., Henion, J.D.: Detection of noncovalent receptorligand complexes by mass spectrometry. J. Am. Chem. Soc. 113, 62946296 (1991)

2. Ganem, B., Li, Y.T., Henion, J.D.: Observation of noncovalent enzyme-substrate and enzyme-product complexes by ion-spray mass spectrometry. J. Am. Chem. Soc. 113, 7818-7819 (1991)

3. Katta, V., Chait, B.T.: Observation of the heme-globin complex in native myoglobin by electrospray-ionization mass spectrometry. J. Am. Chem. Soc. 113, 8534-8535 (1991)

4. Greig, M.J., Gaus, H., Cummins, L.L., Sasmor, H., Griffey, R.H.: Measurement of macromolecular binding using electrospray mass spectrometry. Determination of dissociation constants for oligonucleotide: serum albumin complexes. J. Am. Chem. Soc. 117, 10765-10766 (1995)

5. Lim, H., Hsieh, Y.L., Ganem, B., Henion, J.: Recognition of cell-wall peptide ligands by vancomycin group antibiotics: Studies using ion spray mass spectrometry. J. Mass Spectrom. 30, 708-714 (1995)

6. Loo, J.A., Peifeng, H., McConnell, P., Tom Mueller, W., Sawyer, T.K., Thanabal, V.: A study of Src SH2 domain protein-phosphopeptide binding interactions by electrospray ionization mass spectrometry. $J$. Am. Soc. Mass Spectrom. 8, 234-243 (1997)

7. Zhu, M.M., Rempel, D.L., Du, Z., Gross, M.L.: Quantification of protein-ligand interactions by mass spectrometry, titration, and H/D exchange: PLIMSTEX. J. Am. Chem. Soc. 125, 5252-5253 (2003)

8. Roulhac, P.L., Powell, K.D., Dhungana, S., Weaver, K.D., Mietzner, T. A., Crumbliss, A.L., Fitzgerald, M.C.: SUPREX (Stability of unpurified proteins from rates of $H / D$ exchange) analysis of the thermodynamics of synergistic anion binding by Ferric-Binding Protein (FbpA), a bacterial transferrin. Biochemistry 43, 15767-15774 (2004)

9. Bieth, J.: In: Fritz, H., Tschesche, H., Greene, L.J., Truscheit, E. (eds.) Bayer Symposium V, Proteinase Inhibitors, pp. 463-469. Springer Verlag, New York (1974)

10. van Dongen, W.D., Heck, A.J.R.: Binding of selected carbohydrates to apo-concanavalin A studied by electrospray ionization mass spectrometry. Analyst 125, 583-589 (2000)

11. Clark, S.M., Konermann, L.: Determination of ligand-protein dissociation constants by electrospray mass spectrometry-based diffusion measurements. Anal. Chem. 76, 7077-7083 (2004)

12. Sun, J., Kitova, E.N., Klassen, J.S.: Method for stabilizing proteinligand complexes in nanoelectrospray ionization mass spectrometry. Anal. Chem. 79, 416-425 (2007)

13. Wang, W., Kitova, E.N., Klassen, J.S.: Influence of solution and gas phase processes on protein-carbohydrate binding affinities determined by nanoelectrospray Fourier transform ion cyclotron resonance mass spectrometry. Anal. Chem. 75, 4945-4955 (2003)

14. Wang, W., Kitova, E.N., Sun, J., Klassen, J.S.: Blackbody infrared radiative dissociation of nonspecific protein-carbohydrate complexes produced by nanoelectrospray ionization: The nature of the noncovalent interactions. J. Am. Soc. Mass Spectrom. 16, 1583-1594 (2005)

15. Peschke, M., Verkerk, U.H., Kebarle, P.: Features of the ESI mechanism that affect the observation of multiply charged noncovalent protein complexes and the determination of the association constant by the titration method. J. Am. Soc. Mass Spectrom. 15, 1424-1434 (2004)

16. Daubenfeld, T., Bouin, A.-P., van der Rest, G.: A deconvolution method for the separation of specific versus nonspecific interactions in noncovalent protein-ligand complexes analyzed by ESI-FT-ICR mass spectrometry. J. Am. Soc. Mass Spectrom. 17, 1239-1248 (2006)

17. Sun, J., Kitova, E.N., Wang, W., Klassen, J.S.: Method for distinguishing specific from nonspecific protein-ligand complexes in nanoelectrospray ionization mass spectrometry. Anal. Chem. 78, 3010-3018 (2006)

18. Touboul, D., Maillard, L., Grässlin, A., Moumne, R., Seitz, M., Robinson, J., Zenobi, R.: How to deal with weak interactions in noncovalent complexes analyzed by electrospray mass spectrometry: Cyclopeptidic inhibitors of the nuclear receptor coactivator 1-STAT6. J. Am. Soc. Mass Spectrom. 20, 303-311 (2009)

19. Schmidt, A., Bahr, U., Karas, M.: Influence of pressure in the first pumping stage on analyte desolvation and fragmentation in nano-ESI MS. Anal. Chem. 73, 6040-6046 (2001)

20. Tahallah, N., Pinkse, M., Maier, C.S., Heck, A.J.: The effect of the source pressure on the abundance of ions of noncovalent protein assemblies in an electrospray ionization orthogonal time-of-flight instrument. Rapid Commun. Mass Spectrom. 15, 596-601 (2001)

21. Sanglier, S., Atmanene, C., Chevreux, G., Dorsselaer, A.V.: Nondenaturing mass spectrometry to study noncovalent protein/protein and protein/ligand complexes: technical aspects and application to the determination of binding stoichiometries. Methods Mol. Biol. 484, 217-243 (2008)

22. Bagal, D., Kitova, E.N., Liu, L., El-Hawiet, A., Schnier, P.D., Klassen, J.S.: Gas phase stabilization of noncovalent protein complexes formed by electrospray ionization. Anal. Chem. 81, 7801-7806 (2009)

23. Tjernberg, A., Carnö, S., Oliv, F., Benkestock, K., Edlund, P.-O., Griffiths, W.J., Hallén, D.: Determination of dissociation constants for protein-ligand complexes by electrospray ionization mass spectrometry. Anal. Chem. 76, 4325-4331 (2004)

24. Atmanene, C., Laux, A., Glattard, E., Muller, A., Schoentgen, F., Metz-Boutigue, M.-H., Aunis, D., Van Dorsselaer, A., Stefano, G. B., Sanglier-Cianférani, S., Goumon, Y.: Characterization of human and bovine phosphatidylethanolamine-binding protein (PEBP/RKIP) interactions with morphine and morphine-glucuronides determined by noncovalent mass spectrometry. Med. Sci. Monit. 15, BR178-187 (2009)

25. Bernier, I., Jollés, P.: Purification and characterization of a basic $23 \mathrm{kDa}$ cytosolic protein from bovine brain. Biochim. Biophys. (BBA)-Prot. Struct. Mol. Enzymol. 790, 174-181 (1984)

26. Beaufour, M., Vaillant, A.T., Schoentgen, F., Cadene, M.: Mass Spectrometric Characterization of the Interaction Between PEBP/RKIP and Locostatin, 24th Annual Conference of the French Society for Mass Spectrometry. Pau, France (2007)

27. Gabant, G., Beaufour, M., Schoentgen, F., Cadene, M.: Towards a Dissection of the Molecular Mechanism of Binding of Locostatin to the 
PEBP/RKIP Protein, a Metastasis Suppressor, 25th Annual Conference of the French Society for Mass Spectrometry, Grenoble, France (2008)

28. Limbach, P.A., Crain, P.F., McCloskey, J.A.: Molecular mass measurement of intact ribonucleic acids via electrospray ionization quadrupole mass spectrometry. J. Am. Soc. Mass Spectrom. 6, 27-39 (1995)

29. Jaquillard, L., Gabant, G., Schoentgen, F., Agrofoglio, L., Cadene, M.: Noncovalent Interactions Between the PEBP/RKIP Protein and Nucleotide analogs: 57th ASMS Conference on Mass Spectrometry and Allied Topics. Philadelphia, PA (2009)

30. Bucquoy, S., Jollès, P., Schoentgen, F.: Relationships between molecular interactions (nucleotides, lipids and proteins) and structural features of the bovine brain 21-kDa protein. Eur. J. Biochem. 225, 1203-1210 (1994)

31. Zhang, S., Van Pelt, C.K., Wilson, D.B.: Quantitative determination of noncovalent binding interactions using automated nanoelectrospray mass spectrometry. Anal. Chem. 75, 3010-3018 (2003)

32. Straume, M., Freire, E.: Two-dimensional differential scanning calorimetry: simultaneous resolution of intrinsic protein structural energetics and ligand binding interactions by global linkage analysis. Anal. Biochem. 203, 259-268 (1992)

33. Wiseman, T., Williston, S., Brandts, J.F., Lin, L.N.: Rapid measurement of binding constants and heats of binding using a new titration calorimeter. Anal. Biochem. 179, 131-137 (1989)

34. Jones, C.L., Fish, F., Muccio, D.D.: Determination of RNase A/2'cytidine monophosphate binding affinity and enthalpy by a global fit of thermal unfolding curves. Anal. Biochem. 302, 184-190 (2002)

35. Park, S., Rath, O., Beach, S., Xiang, X., Kelly, S.M., Luo, Z., Kolch, W., Yeung, K.C.: Regulation of RKIP binding to the N-region of the Raf-1 kinase. FEBS Lett. 580, 6405-6412 (2006)
36. Schindler, M., Assaf, Y., Sharon, N., Chipman, D.M.: Mechanism of lysozyme catalysis: Role of ground-state strain in subsite D in hen eggwhite and human lysozymes. Biochemistry 16, 423-431 (1977)

37. Burbaum, J.J., Knowles, J.R.: Internal thermodynamics of enzymes determined by equilibrium quench: Values of Kint for enolase and creatine kinase. Biochemistry 28, 9306-9317 (1989)

38. Sun, N., Soya, N., Kitova, E.N., Klassen, J.S.: Nonspecific interactions between proteins and charged biomolecules in electrospray ionization mass spectrometry. J. Am. Soc. Mass Spectrom. 21, 472481 (2010)

39. El-Hawiet, A., Kitova, E.N., Liu, L., Klassen, J.S.: Quantifying labile protein-ligand interactions using electrospray ionization mass spectrometry. J. Am. Soc. Mass Spectrom. 21, 1893-1899 (2010)

40. Robinson, C.V., Chung, E.W., Kragelund, B.B., Knudsen, J., Aplin, R. T., Poulsen, F.M., Dobson, C.M.: Probing the nature of noncovalent interactions by mass spectrometry. A study of protein-CoA ligand binding and assembly. J. Am. Chem. Soc. 118, 8646-8653 (1996)

41. Wu, Q., Gao, J., Joseph-McCarthy, D., Sigal, G.B., Bruce, J.E., Whitesides, G.M., Smith, R.D.: Carbonic anhydrase-inhibitor binding: From solution to the gas phase. J. Am. Chem. Soc. 119, 1157-1158 (1997)

42. Cheetham, J.C., Artymiuk, P.J., Phillips, D.C.: Refinement of an enzyme complex with inhibitor bound at partial occupancy: Hen eggwhite lysozyme and tri- $N$-acetylchitotriose at $1.75 \AA$ resolution. J. Mol. Biol. 224, 613-628 (1992)

43. Jecklin, M.C., Touboul, D., Bovet, C., Wortmann, A., Zenobi, R.: Which electrospray-based ionization method best reflects protein-ligand interactions found in solution? A comparison of ESI, nanoESI, and ESSI for the determination of dissociation constants with mass spectrometry. J. Am. Soc. Mass Spectrom. 19, 332-343 (2008) 